\title{
Exercise on land or in water?
}

This article was published in the following Dove Press journal:

International Journal of General Medicine

30 March 2012

Number of times this article has been viewed

\section{Alain Boussuges' \\ Olivier Gavarry ${ }^{2}$}

'French Armed Forces Biomedical Research Institute, Brétigny sur Orge and UMR MD2, Aix-Marseilles University, Marseilles, France;

${ }^{2}$ Engineering Laboratory for Handicaps. South University of Toulon - Var, La Garde, France
Correspondence: Alain Boussuges Institut de Recherche Biomédicale des Armées, BP 73-9|223, Brétigny sur Orge, Paris, France

Tel +33I 69237443

Fax +33I 69237002

Email alain.boussuges@univmed.fr
We have read with interest the study published in the International Journal of General Medicine entitled "Hypotensive response after water-walking and land walking exercise sessions in healthy trained and untrained women" by Rodriguez et al. ${ }^{1}$ In this study, the authors investigated cardiovascular changes induced by walking in water in comparison with walking on land. Water exercises are commonly used in rehabilitation programs, particularly patients with mobility problems. Recently, some studies have suggested that exercise performed in water could improve cardiovascular function. ${ }^{2}$

Thermoneutral headout water immersion leads to important hemodynamic alterations, such as increases in both cardiac preload and cardiac output and a decrease in peripheral vascular resistance. ${ }^{3}$ An increase in cardiac output induces an increase in peripheral blood flow and subsequently an increase in endothelial shear stress. This mechanism could be responsible for greater improvement in endothelial function after water gymnastics in comparison with land exercise. Consequently, water exercises might be of particular interest for patients with endothelial dysfunction. However, clinical interest in water exercise for the treatment of cardiovascular disease remains to be established. Further studies are needed to compare the cardiovascular effects of exercises performed in water and on land.

We have some concerns about the methods used in the study reported by Rodriguez et $\mathrm{al}^{1}$ whereby all subjects were immersed in a bath and remained standing for 60 minutes before the exercise period. The temperature of the water was adjusted to $30^{\circ} \mathrm{C} \pm 1{ }^{\circ} \mathrm{C}$. The thermoconductivity of water is 25 times greater than that of air. Consequently, the loss of body heat in water requires that thermal conditions be rigorously controlled. In the study by Rodriguez et $\mathrm{al}^{1}$ the suitability of the water temperature is debatable. Previous studies have determined that for subjects at rest, to provide thermoneutral conditions in water, the temperature of the bath should be maintained between $34^{\circ} \mathrm{C}$ and $35^{\circ} \mathrm{C}$. In exercising volunteers, a thermoneutral water temperature was found to be around $32^{\circ} \mathrm{C}$. To accommodate these conditions, some authors have investigated resting volunteers during headout immersion in water at temperatures between $34^{\circ} \mathrm{C}$ and $35^{\circ} \mathrm{C}$. Subsequently, to provide thermoneutral water temperature during exercise, water temperature was progressively cooled to $32.5^{\circ} \mathrm{C} .4,5$ These water temperature conditions produced a pulmonary arterial temperature in water similar to that on land at any exertion level from $40 \%$ to $100 \%$ of maximal oxygen consumption. ${ }^{5}$ 
In the work performed by Rodriguez et al the water temperature was below thermoneutrality both at rest and during exercise. It has been documented by Park et $a l^{6}$ that headout water immersion at a temperature below $34^{\circ} \mathrm{C}$ or $35^{\circ} \mathrm{C}$ modifies hemodynamic status in comparison with both thermoneutral water immersion and ambient air. During headout water immersion at thermoneutral temperature, cardiac output and stroke volume increased compared with levels in air. At a lower temperature, the increased stroke volume tended to be higher, whereas the heart rate decreased. Furthermore, the decrease in peripheral vascular resistance, commonly observed in thermoneutral water immersion, was attenuated when the temperature was decreased down from $34.5^{\circ} \mathrm{C}$ to $30^{\circ} \mathrm{C}$. Arterial pressure was also altered, and an increase in diastolic arterial pressure was recorded at temperatures lower than $34.5^{\circ} \mathrm{C}$.

Lastly, it has been demonstrated that autonomic control of the cardiovascular system is variously affected depending on water temperature. During thermoneutral headout water immersion, decreased sympathetic activity (both cardiac and vascular) and a shift towards cardiac parasympathetic predominance have been recorded. ${ }^{7}$ In contrast, immersion in slightly cold water (temperature $25^{\circ} \mathrm{C}-30^{\circ} \mathrm{C}$ ), leads to sympathetic vascular and parasympathetic cardiac hyperactivity. ${ }^{8}$

Despite these limitations, the findings of Rodriguez et al are interesting. The greater post exercise decrease in blood pressure recorded in untrained healthy women after walking in chest-deep water in comparison with walking on land suggests an enhancement of the cardiovascular outcomes of exercise in water. Furthermore, this study can be considered to be relevant to assessments made in real clinical practice. Indeed, rehabilitation programs are frequently performed in swimming pools at water temperatures below thermoneutral conditions (between $28^{\circ} \mathrm{C}$ and $31^{\circ} \mathrm{C}$ ). Further studies are needed to assess the benefit of water exercises in the management of cardiac patients.

\section{References}

1. Rodriguez D, Silva V, Prestes J, et al. Hypotensive response after water-walking and land-walking exercise sessions in healthy trained and untrained women. Int J Gen Med. 2011;4:549-554.

2. Laurent M, Daline T, Malika B, et al. Training-induced increase in nitric oxide metabolites in chronic heart failure and coronary artery disease: an extra benefit of water-based exercises? Eur J Cardiovasc Prev Rehabil. 2009;16:215-221.

3. Arborelius M Jr, Ballidin UI, Lilja B, Lundgren CE. Hemodynamic changes in man during immersion with the head above water. Aerosp Med. 1972;43:592-598.

4. Connelly TP, Sheldahl LM, Tristani FE, et al. Effect of increased central blood volume with water immersion on plasma catecholamines during exercise. J Appl Physiol. 1990;69:651-656.

5. Christie JL, Sheldahl LM, Tristani FE, et al. Cardiovascular regulation during head-out water immersion exercise. J Appl Physiol. 1990;69: 657-664.

6. Park KS, Choi JK, Park YS. Cardiovascular regulation during water immersion. Appl Human Sci. 1999;18:233-241.

7. Miwa C, Sugiyama Y, Mano T, Iwase S, Matsukawa T. Spectral characteristics of heart rate and blood pressure variabilities during head-out water immersion. Environ Med. 1996;40:91-94.

8. Mourot L, Bouhaddi M, Gandelin E, et al. Cardiovascular autonomic control during short-term thermoneutral and cool head-out immersion. Aviat Space Environ Med. 2008;79:14-20. 


\section{Response}

\section{Danilo Sales Bocalini ${ }^{1,2}$ \\ Daniel Rodriguez ${ }^{1,3}$ \\ Roberta Luksevicius Rica ${ }^{1,4}$ \\ Andrey Jorge Serra ${ }^{5}$ \\ Francisco Luciano Pontes J $\mathrm{r}^{6}$}

'Gama Filho University, Rio de Janeiro, '2Department of Medicine, Federal University of São Paulo, Escola Paulista de Medicina, São Paulo, ${ }^{3}$ São Judas Tadeu University, São Paulo, ${ }^{4}$ Department of Physical Education, Arbos College, São Bernardo do Campo, São Paulo, ${ }^{5}$ Department of Physical Education and Laboratory of Rehabilitation Science, Nove de Julho University, São Paulo, ${ }^{6}$ School of Arts, Sciences and Humanities, University of São Paulo, São Paulo, Brazil

Correspondence: Danilo Sales Bocalini

Rua Ari Barroso 68, Apto 105, Torre I, Ferrazopolis, São Bernardo do

Campo, SP 097902-240, Brazil

$\mathrm{Tel}+55$ I I 98923897

Fax +55 II 5587 I 700

Email bocalini@fcr.epm.br

We appreciate the comments of Doctors Boussuges and Gavarry about our study. Water exercise is frequently utilized in several rehabilitation programs, especially musculoskeletal disease, ${ }^{1-3}$ and more recently some studies had been showed increments in functional fitness in elderly people. ${ }^{4-7}$ Water-based exercise has been widely promoted as the optimal type of exercise because it reduces weightbearing stresses on the skeletal joints and provides therapeutic benefits for orthopedic conditions. ${ }^{7}$

Regarding water, two points should be mentioned, ie, temperature and immersion. With regard to temperature and cardiovascular effects, we agree with Boussuges and Gavarry. The temperature used in our study is not thermoneutral, but a lot of research has used water-based protocols with temperatures below thermoneutrallity. ${ }^{4,5,79}$ Further, according to the Aquatic Exercise Association (AEA), ${ }^{10}$ the recommended temperature for aquatic fitness is between $28^{\circ} \mathrm{C}$ and $30^{\circ} \mathrm{C}$. However, the temperature used in studies ${ }^{4,5,11}$ of our group varies between $28^{\circ} \mathrm{C}$ and $31^{\circ} \mathrm{C}$, corresponding to older people as recommended to AEA $10 .{ }^{4,5}$ Another important point relates to the control of immersion, whereby our data was different from those of other studies, ${ }^{12,13}$ and any conflicting results could be accounted for by differences in water temperature.

Despite these issues, our aim was to evaluate post exercise decreases in blood pressure in conditions usually found in real clinical practice, and shown by Rodriguez et al. To the best of our konowledge the results presented to Rodriguez et al, is the first to indicate positive effects on the cardiovascular system when assessing the post exercise decrease in blood pressure, but more studies are needed to investigate the role of water-based exercise on physiological mechanisms in different populations. As an example, a recent publication ${ }^{14}$ showed that a combination of land endurance and water callisthenic exercises in patients with stable chronic heart failure was well tolerated, with significant improvements in ventricular ejection fraction, a decrease in heart rate, and a reduction in diastolic blood pressure.

\section{Disclosure}

The authors report no conflicts of interest in this work.

\section{References}

1. Hall J, Swinkels A, Briddon J, McCabe CS. Does aquatic exercise relieve pain in adults with neurologic or musculoskeletal disease? A systematic review and meta-analysis of randomized controlled trials. Arch Phys Med Rehabil. 2008;89:873-883.

2. Bartels EM, Lund H, Hagen KB, Dagfinrud H, Christensen R, Danneskiold-Samsøe B. Aquatic exercise for the treatment of knee and hip osteoarthritis. Cochrane Database Syst Rev. 2007;4:CD005523.

3. Valtonen A, Pöyhönen T, Sipilä S, Heinonen A. Maintenance of aquatic training-induced benefits on mobility and lower-extremity muscles among persons with unilateral knee replacement. Arch Phys Med Rehabil. 2011;92:1944-1950.

4. Bocalini DS, Serra AJ, Murad N, Levy RF. Water- versus land-based exercise effects on physical fitness in older women. Geriatr Gerontol Int. 2008;8:265-271.

5. Bocalini DS, Serra AJ, Rica RL, Dos Santos L. Repercussions of training and detraining by water-based exercise on functional fitness and quality of life: a short-term follow-up in healthy older women. Clinics (São Paulo). 2010;65:1305-1309.

6. Hale LA, Waters D, Herbison P. A randomized controlled trial to investigate the effects of water-based exercise to improve falls risk and physical function in older adults with lower-extremity osteoarthritis. Arch Phys Med Rehabil. 2012;93:27-34.

7. Takeshima N, Rogers ME, Watanabe E. Water based exercise improves health-related aspects of fitness in older women. Med Sci Sports Exerc. 2002;33:544-551.

8. Pontes Jr FL, Bacurau RF, Moraes MR, et al. Kallikrein kinin system activation in post-exercise hypotension in water running of hypertensive volunteers. Int Immunopharmacol. 2008;8:261-266.

9. Fujishima K, Shimizu T. Body temperature, oxygen uptake and heart rate during walking in water and on land at an exercise intensity based on RPE in elderly men. J Physiol Anthropol Appl Human Sci. 2003;22:83-88.

10. Aquatic Exercise Association. Aquatic Fitness Manual. 5th ed. Champaign, IL: Human Kinetics; 2006.

11. Rodriguez D, Silva V, Prestes J, et al. Hypotensive response afterwaterwalking and land-walking exercise sessions in healthy trained and untrained women. Int J Gen Med. 2011;4:549-554.

12. Graef FI, Kruel LFM. Heart rate and perceived exertion at aquatic environment: differences in relation to land environment and applications for exercise prescription - a review. Rev Bras Med Esporte. 2006;12: 221-228. Brazilian.

13. Silva EM, Kruel LFM. Walking on land and in water: a review study about the comparison of neuromuscular and cardiorespiratory responses. Rev Bras Med Esporte. 2008;14(6):553-556. Brazilian.

14. Teffaha D, Mourot L, Vernochet P, et al. Relevance of water gymnastics in rehabilitation programs in patients with chronic heart failure or coronary artery disease with normal left ventricular function. J Card Fail. 2011;17:676-683. 


\section{Publish your work in this journal}

The International Journal of General Medicine is an international, peer-reviewed open-access journal that focuses on general and internal medicine, pathogenesis, epidemiology, diagnosis, monitoring and treatment protocols. The journal is characterized by the rapid reporting of reviews, original research and clinical studies across all disease areas.

A key focus is the elucidation of disease processes and management protocols resulting in improved outcomes for the patient. The manuscript management system is completely online and includes a very quick and fair peer-review system. Visit http://www.dovepress.com/ testimonials.php to read real quotes from published authors.

Submit your manuscript here: http://www.dovepress.com/international-journal-of-general-medicine-journal 